\title{
THE SIGNIFICANCE OF THE SENSE OF COHERENCE FOR VARIOUS COPING RESOURCES IN STRESS SITUATIONS USED BY POLICE OFFICERS IN ON-THE-BEAT SERVICE
}

\author{
ANNA M. DÅDERMAN ${ }^{1}$ and DANIEL DE COLLI ${ }^{1,2}$ \\ ${ }^{1}$ University West, Trollhättan, Sweden \\ Department of Social and Behavioural Studies, Division of Psychology and Organizational Studies \\ ${ }^{2}$ Division of Serious Criminal Offenses, Västerås, Sweden \\ Police Department of Västmanland
}

\begin{abstract}
Background: Police officers meet many stressors as part of their occupation. The psychological resource "sense of coherence" (SOC) protects against ill-health, but its impact on coping resources for stress situations has not been studied in the population of police officers. Different approaches to investigate the significance of SOC for different outcomes have been identified in literature, leading to some difficulties in the interpretation and generalization of results. The aim was therefore to explore SOC and the coping resources, and to examine the significance of SOC for various coping resources for stress using different models in a sample of Swedish police officers providing on-the-beat service. Materials and Methods: One hundred and one police officers (age: mean $=33$ years, $\mathrm{SD}=8 ; 29$ females) were included, and the Orientation to Life Questionnaire (SOC-29) and the Coping Resources Inventory (CRI) were used. The dependent variable in each regression analysis was one of the coping resources: cognitive, social, emotional, spiritual/philosophical, physical, and a global resource. Global SOC-29 and/or its components (comprehensibility, manageability, and meaningfulness) were investigated as independent variables. Results: All CRI and SOC-29 scores except for that of spiritual/philosophical resources were higher than those of reference groups. Manageability was the most important component of SOC for various coping resources in stress situations used by police officers. Conclusion: A deeper study of manageability will give useful information, because this component of SOC is particularly significant in the variation in resources used by police officers to cope with stress. Salutogenesis, the origin of well-being, should be more in focus of future research on workplaces with a high level of occupational stress.
\end{abstract}

Key words:

SOC, Comprehensibility, Manageability, Meaningfulness, CRI, Police officers

\footnotetext{
This work was performed within a project DNR 2012/1196 B 22 entitled "Significance of human factors such as self-esteem, personality traits, sense of coherence and coping resources for attitudes to crisis management”. Project Manager: Anna M., Dåderman, M.D., Ph.D., Associate Professor.

Received: August 27, 2013. Accepted: December 16, 2013.

Corresponding author: A.M. Dåderman, Department of Social and Behavioural Studies, Division of Psychology and Organizational Studies, University West, SE-461 86 Trollhättan, Sweden (e-mail: anna.daderman@hv.se).
} 


\section{INTRODUCTION}

The literature on police stress is extensive (there are over 600 review articles on stress in police officers), but the existing knowledge on coping resources in police officers is sparse [1]. The psychological resource "sense of coherence" (SOC) [2] protects against illhealth [3,4], but its impact on coping resources for stress situations has not been studied in the population of police officers. This study attempts to fill this gap in the literature. Moreover, different regression "models" are used when researchers investigate the significance of SOC for various outcomes. Independent variable(s) may be defined as: (1) a global concept of SOC [5]; (2) the three components (see below) of SOC [6]; or (3) a global one-factor construct, together with the three components [7]. The tendency to extrapolate the findings when only one model is used may lead to questions about the interpretation and generalizability of the findings. In this study, we solved the problem by defining and comparing with one another the above mentioned models.

Police officers may be under considerable stress due to the nature of their occupation, which is one of the most stressful [8]. Killing somebody in the course of one's work is the most severe stressor that can be experienced, followed by the death of a fellow officer, experiencing physical attack, and contact with a battered child [9]. Organizational stress may arise from such factors as inadequate departmental support, insufficient remuneration, and extensive shift work [10]. Kassen and DiLalla [11] have recently identified five work stressors most frequently stated by employees in a specialized unit of the South African police service: insufficient remuneration, poor public perception of police work, work overload, problems with transfer policies, and frustrations with the criminal justice system.

Several individual characteristics of a police officer may play a role in how he or she handles stress, and the extent to which he or she needs support to cope with difficult experiences. It may be objectively difficult to cope with an event, such as dealing with a severely mangled human body after a suicide on a train track. Some drug-related violent crimes may provoke a furious attack and sadistic treatment of the victims [12], and the police officer must control a dangerous situation while arresting such a violent person. One police officer may experience the situation as very difficult to manage, while another may experience it as a routine operation. Certain personality traits and attitudes are more suitable than others for this profession, and the capacity to adapt to work-related stress and potentially traumatic events are, therefore, traits that are examined during the recruitment procedures for police education. It is also important to keep in mind that learning from experience enriches police officers.

The concept of SOC focuses on resources and strengths, and not on the negative consequences of actions or life events [2]. SOC is defined by Antonovsky [2] as: "A global orientation that expresses the extent to which one has a pervasive, enduring though dynamic feeling of confidence that (a) the stimuli deriving from one's internal and external environments in the course of living are structured, predictable and explicable; (b) the resources are available to one to meet the demands posed by these stimuli; and these demands are challenges, worthy of investment and engagement".

According to this definition, people who see the world as comprehensible, manageable and meaningful, despite the presence of various stressors, have a high SOC and are on the healthy side of the "health-illness" continuum. Such people can maintain their health and improve it, despite being subject to various stressors. SOC comprises three, theoretically derived, components:

1. Comprehensibility is the extent to which a person experiences internal and external stimuli as rationally graspable. He or she experiences the information 
that is received as organized, coherent, structured and clear.

2. Manageability is the degree to which a person feels that there are resources at his or her disposal (such resources that are controllable), with the help of which he or she can meet the demands of the stimuli to which he or she is exposed.

3. Meaningfulness is a motivational component that determines if a person perceives an event or situation as challenging and worthy of emotional investment and commitment, rather than as a burden and something to be avoided.

Two widely used scales for measuring SOC are SOC-13 and SOC-29, and we used the latter. It comprises 29 items, and has been used to study police officers in Finland [e.g. 13], Poland [e.g. 14], and South Africa [e.g. 11]. Previous research has often lacked adequate knowledge regarding the significance of specific domains of SOC for the various coping resources used by police officers in stress situations. The structure of SOC has been conceptualized by means of confirmatory factor analysis as a single general factor SOC that consists of three interrelated firstorder factors [15].

Lazarus and Folkman [16] stated that police officers who do not employ coping strategies usually remain stressed. They also stated that coping comprises "realistic and flexible thoughts and acts that solve problems and thereby reduce stress" (p. 190). The term "coping" describes the use of various coping resources, and the attainment of a psychological resource, SOC, and thus, coping with stressors in life and resources in stress situations are worth studying. We focus on adaptive coping strategies in the work presented here, not on maladaptive strategies (such as using or abusing substances).

Coping resources are defined by Marting and Hammer [17] as those resources "inherent in individuals that enable them to handle stressors more effectively, to experience fewer or less intense symptoms upon exposure to a stressor, or to recover faster from exposure" (p. 2), and it is assumed that they play a mediating role in the coping process. They may be measured by the Coping Resources Inventory (CRI) [17]:

1. Cognitive resources enable a person to maintain a positive view of himself/herself and others, and to maintain a generally optimistic attitude. The role of a positive self-concept in the adaptation to stress is wellknown [18].

2. Social resources are provided by the social networks to which a person belongs that are able to provide support in times of stress.

3. Emotional resources enable a person to accept and express all kinds of affect, based on the premise that a range of emotional responses aids in relieving the long-term negative consequences of stress.

4. Spiritual/philosophical resources determine the degree to which the actions of a person are guided by stable and consistent values derived from religious, familial, or cultural traditions, or from personal philosophy. Such values may serve to give a meaning to potentially stressful events and to prescribe strategies for responding effectively.

5. Physical resources reflect the degree to which a person carries out health-promoting activities believed to contribute to increased physical well-being. It is assumed that physical well-being can decrease the level of negative response to stress, and enable faster recovery.

CRI has not been used to examine police officers, but it has been used to study coping resources in other populations [19-21]. Cognitive and physical resources were the best predictors of various forms of symptoms in a study by Zeidner and Hammer [21].

SOC is worth studying because:

1. People with high values of SOC report high values of the quality of life. SOC may be a dynamic concept that increases through the experience of stress management and learning from past situations. 
2. SOC has been implemented in the basic and advanced education of Swedish police officers [22], but it has not been examined in Swedish police officers.

3. Three theoretically derived components make up SOC, and it is possible to study them as an entity, separately or both, but researchers are not unanimous on this [23]. This may lead others to fail to examine other alternatives, and thus, fail to examine their research questions, if they use the global SOC only.

4. SOC plays a role as a construct focused on conscious choice, and we believe that it will therefore be a good predictor of adaptive coping resources in the population of police officers.

\section{AIMS AND RATIONALE}

The main aim of the work presented here was to explore SOC and the coping resources possessed by police officers, that is, their different abilities to manage and recover from stress. A further aim was to examine the significance of SOC for various coping resources for stress as: (a) a global concept; (b) a concept comprising the three theoretically based components; and (c) a global one-factor construct, together with the three components. We define and compare three multiple regression "models" in this study.

First, a global SOC model, in which the global SOC concept with all 29 items is used as an independent variable to test whether the one-factor model is sufficient to predict how officers use the various coping resources. Second, a triple-correlated SOC component model, in which the three theoretical components (comprehensibility, manageability and meaningfulness) are used as independent variables to test whether the triple-component model is sufficient to predict how officers use the various coping resources. Finally, the global SOC together with the triplecorrelated SOC component model, in which all 29 items of the global SOC and the three theoretical components (comprehensibility, manageability and meaningfulness) are used as independent variables to test whether the three-component model together with the global SOC model are sufficient to predict how officers use the various coping resources.

Different results are expected from these three models. If the global SOC alone serves as a significant predictor in the stepwise multiple regression analyses in the combined model, we can conclude that the global SOC is sufficient as a predictor, because it makes a significant contribution to explaining the maximum amount of variance in the criterion variable. However, if the results show that an individual component serves as a significant predictor, it may be necessary to discuss, and possibly also revise, the previous findings in which the global SOC was used as a predictor.

The following research questions were formulated:

- Are any dimensions of SOC stronger in Swedish police officers compared with a similar sample?

- Are any dimensions of CRI stronger in Swedish police officers compared with a normative sample?

- Are there any relationships between CRI and SOC?

It was hypothesized that Swedish police officers providing on-he-beat service would have a stronger SOC and higher values of CRI than comparison samples, because they must undergo a special education in fundamental police tactics that includes stress management and the development of communication skills [22].

\section{MATERIALS AND METHODS}

\section{Selection}

The study was carried out in Swedish police officers providing on-the-beat service. Those providing this kind of work must be certified in fundamental police tactics. This education comprises theory and practical exercises in stress and conflict management based on a communicative approach, well-being and SOC. The participants 
were working at a police department in the central Swedish county of Västmanland, one of the 21 police departments in Sweden. We excluded the "Street Violence Group" (4 persons), "Street Drug Group" (3 persons), an "Independent Service Group" (3 persons), one duty officer and one external commander, due to their limited availability.

It was not clear how many of the serving police officers were undergoing cadet service (a part of their training course). This is because the officers had individual schedules under which they moved between the various sections of the police department. The number of potential police officers in the study group was 143 . This means that 24 police officers were not present during the data collection, due to such factors as training, vacation, illness and participation in other missions. The response rate was 85\% (119 questionnaires were distributed and 101 completed questionnaires were collected).

\section{Participants}

The number of participants was 101 (29 women and $72 \mathrm{men})$. The mean age of the participants was 33 years $(\mathrm{SD}=8)$ - the youngest was 22 and the oldest was 62 years old. The mean duration of service was five years and four months ( $\mathrm{SD}=9$ years). Forty-six participants had completed another college or university education before they attended the police academy.

There were more than twice as many men as women in the sample. The mean age of women $(\mathrm{M}=30, \mathrm{SD}=6)$ was significantly lower $(\mathrm{t}=2.28, \mathrm{p}=0.025)$ than that of men $(\mathrm{M}=34, \mathrm{SD}=9)$, but they did not differ in the duration of service.

\section{Measures}

Orientation to Life Questionnaire (SOC-29)

SOC was measured using the Orientation to Life Questionnaire [2]. The SOC-29 is reliable, valid, and can be applied across cultures to measure how people manage stressful situations and stay well [24]. The scale consists of 29 items and is used to measure:

1. Comprehensibility (11 items), using questions such as: "Has it happened that you were surprised by the behavior of people whom you thought you knew well?".

2. Manageability (10 items), using questions such as: "Has it happened that people on whom you counted disappointed you?".

3. Meaningfulness (8 items), using questions such as: "Do you have the feeling that you don't really care about what goes on around you?".

The respondent is asked to select a response on a 7-point semantic differential scale with two anchoring phrases (7 - maximum, 1 - minimum). Higher scores indicate a stronger SOC. Eriksson and Lundström [24] reviewed the validity and reliability of the scale in 30 countries and showed that Cronbach's $\alpha$ [25] for the subscales and the global measure ranges between 0.84 and 0.93 . (Cronbach's $\alpha$ measures the internal consistency and reliability. It ranges from 0 to 1 , with values of $0.60-0.70$ deemed to be the lower limit of acceptability [26]). The internal consistency of the global measure in the present study was 0.88 . It was 0.76 for the comprehensibility and manageability subscales, and it was 0.77 for the meaningfulness subscale.

\section{Coping Resources Inventory (CRI)}

This measure was developed by Marting and Hammer [17] and is a self-assessment questionnaire with 60 items (translated into Swedish by Ekecrantz and Norman [27]). CRI has been developed to identify a person's currently available resources for managing stress, rather than examining deficiencies in coping resources. It is divided into five types of resource:

- cognitive resources (9 items), analyzed by such statements as: "I actively look for the positive side of people and situations"; 
- social resources (13 items), analyzed by such statements as: "I am part of a group, other than my family, that cares about me";

- emotional resources (16 items), analyzed by such statements as: "I can show it when I am sad";

- spiritual/philosophical resources (11 items), analyzed by such statements as: "I accept problems that I cannot change";

- physical resources (11 items), such statements as: "I have plenty of energy".

Responses to all items are made on 4-point Likert-type scales that specify how often a person has engaged in a described behavior during the past 6 months (Never or rarely, Sometimes, Often, and Almost always or always). A higher score indicates better resources for coping. Cronbach's $\alpha$ is 0.91 for the total scale, and $0.56-0.87$ for the types of resources [17]; the test-retest reliability is 0.73 . The internal consistency of the global measure was 0.90 in the present study, while it was 0.62 for cognitive resources, 0.75 for social resources, 0.83 for emotional resources, 0.64 for spiritual/philosophical resources, and 0.80 for physical resources. Marting and Hammer [17] show that constructs for the cognitive, social and emotional resources overlap to a certain degree, possibly due to a person with positive views also having a supportive social network and being aware and able to express emotions. This overlapping was present in our study $(0.65 ; 0.58)$.

\section{Social Desirability Scale}

The Lie scale from the Eysenck Personality Questionnaire (EPQ) [28], was included as a validation check for socially desirable responding. This scale is a self-assessment questionnaire with 21 items to be answered "Yes" or "No". (It includes such questions as: "Have you ever broken or lost something belonging to someone else?"). Cronbach's $\alpha$ for this scale is satisfactory, generally around 0.80 [29]. The internal consistency of the Lie scale in the present study was 0.70 . There were no significant correlations between social desirability and the study measures, which indicates that giving socially desirable answers did not affect the results from the analyses.

\section{Statistical analyses}

Data screening before the analysis showed that the dependent variables (the different types of coping resources) did not contain any outliers. Levene's test for the equality of variances was non-significant and the data distributions on all study measures were sufficiently close to a normal distribution (skewness was between -0.12 and -0.79 ; kurtosis was between 0.06 and -0.89). A one-sample t-test was used to test the differences between the mean scale scores in the measures obtained from the present sample and those obtained from similar samples of police officers and from normative data. We tested the relationships between study measures using simple and stepwise multiple regression analyses to explore the extent to which the participants' scores on the various types of coping resources were predicted by SOC as a global concept or by SOC as a concept with triple moderately correlated components (independent variables). Values of adjusted $R^{2}$, which takes into account the number of the variables and the number of participants in the model, are presented in this article.

\section{Procedure and ethics}

Self-reporting instruments were administered individually to the participants during a special work session, after permission had been received from the head of the department. The persons running these meetings (usually group leaders) were contacted and asked to distribute and collect the questionnaires. Instructions for participants and information about the study were given on the first page of the questionnaire.

We received the approval from the Research Ethical Review Board at the University West to conduct this research project. Replies were given anonymously. A written consent was obtained from each participant. 


\section{RESULTS}

\section{Descriptive statistics}

Table 1 presents descriptive statistics of SOC, together with comparisons with a similar group [6].

Table 1 shows that the participants had higher mean scale scores than the comparison group for all SOC variables. Antonovsky [30] obtained scores for 21 independent samples that ranged between 117 and 152.6, and thus we have concluded that Swedish police officers have a higher SOC that the group studied by Antonovsky [30].
The mean global SOCscore in women $(\mathrm{M}=144.7, \mathrm{SD}=17.6)$ was significantly lower $(t=2.21, p=0.029)$ than that in men $(\mathrm{M}=152, \mathrm{SD}=13.8)$. The mean comprehensibility score in women $(\mathrm{M}=43.8, \mathrm{SD}=8.3)$ was significantly lower $(\mathrm{t}=2.74, \mathrm{p}=0.007)$ than that in men $(\mathrm{M}=48, \mathrm{SD}=6.3)$. Table 2 presents descriptive statistics of CRI, together with comparisons with an American normative group [17]. Table 2 shows that the participants had higher mean scale scores than the comparison group on all CRI scales except for spiritual/philosophical resources.

There were no gender differences in the CRI scales.

Table 1. SOC variables in a group of Swedish police officers, and comparisons with a group of Polish uniformed professions

\begin{tabular}{|c|c|c|c|c|}
\hline \multirow{2}{*}{ Variable } & \multicolumn{2}{|c|}{$\begin{array}{l}\text { Respondents } \\
(\mathrm{M} \pm \mathrm{SD})\end{array}$} & \multirow{2}{*}{$\mathrm{t}$} & \multirow[b]{2}{*}{$\mathrm{p}$} \\
\hline & $\begin{array}{l}\text { Swedish } \\
(\mathrm{N}=101)\end{array}$ & $\begin{array}{c}\text { Polish }^{\mathrm{a}} \\
(\mathrm{N}=330)^{*}\end{array}$ & & \\
\hline Comprehensibility & $46.77 \pm 7.15$ & $44.77 \pm 9.72$ & 2.48 & 0.015 \\
\hline Manageability & $54.00 \pm 5.54$ & $48.80 \pm 8.57$ & 9.07 & $<0.0001$ \\
\hline Meaningfulness & $44.65 \pm 5.15$ & $39.36 \pm 7.78$ & 11.03 & $<0.0001$ \\
\hline Global SOC & $149.93 \pm 15.27$ & $138.31 \pm 22.78$ & 7.85 & $<0.0001$ \\
\hline
\end{tabular}

SOC - sense of coherence.

$\mathrm{M}$ - mean; SD - standard deviations.

${ }^{a}$ Data (recalculated) from Ogińska-Bulik [6], Table 1, p. 236.

* 70 police officers, 70 firefighters, 60 prison officers, 70 security guards, and 60 city guards.

Table 2. CRI variables in a group of Swedish police officers, and comparisons with a normative American group

\begin{tabular}{|c|c|c|c|c|}
\hline \multirow{2}{*}{ Scale } & \multicolumn{2}{|c|}{$\begin{array}{l}\text { Respondents } \\
(\mathrm{M} \pm \mathrm{SD})\end{array}$} & \multirow{2}{*}{$\mathrm{t}$} & \multirow{2}{*}{$\mathrm{p}$} \\
\hline & $\begin{array}{l}\text { Swedish } \\
(\mathrm{N}=101)\end{array}$ & $\begin{array}{l}\text { American }^{\mathrm{a}} \\
(\mathrm{N}=843)\end{array}$ & & \\
\hline Cognitive & $30.11 \pm 3.17$ & $27.49 \pm 4.54$ & 6.69 & $<0.0001$ \\
\hline Social & $42.02 \pm 4.18$ & $39.35 \pm 6.03$ & 7.26 & $<0.0001$ \\
\hline Emotional & $47.56 \pm 5.92$ & $46.12 \pm 7.49$ & 2.66 & 0.009 \\
\hline Spiritual/philosophical & $27.41 \pm 3.90$ & $32.02 \pm 6.10$ & 11.84 & $<0.0001$ \\
\hline Physical & $33.03 \pm 4.98$ & $28.95 \pm 5.37$ & 8.13 & $<0.0001$ \\
\hline Global & $180.13 \pm 16.31$ & $174.17 \pm 21.88$ & 3.78 & $<0.0001$ \\
\hline
\end{tabular}

CRI - Coping Resources Inventory.

${ }^{a}$ Data from Marting and Hammer [17], Table 2, p. 9.

Other abbreviations as in Table 1. 


\section{A global SOC model}

We initially investigated the correlations between various coping resources and the global SOC. We conducted 6 separate simple regression analyses, each with 1 coping resource as a dependent variable and the global SOC as an independent variable.

The global SOC explained:

- $31.3 \%$ of the variance in cognitive resources, $\mathrm{F}(1,99)=46.53, \mathrm{p}<0.0001$;

- $23.2 \%$ of the variance in social resources, $\mathrm{F}(1,99)=31.17, \mathrm{p}<0.0001$;

- $25.1 \%$ of the variance in emotional resources, $\mathrm{F}(1,99)=34.59, \mathrm{p}<0.0001$;

- $8.4 \%$ of the variance in spiritual/philosophical resources, $\mathrm{F}(1,99)=10.15, \mathrm{p}=0.002$;

- $10.4 \%$ of the variance in physical resources, $\mathrm{F}(1,99)=12.58, \mathrm{p}=0.001$;

- $34.8 \%$ of the variance in global resources to cope with stress, $\mathrm{F}(1,99)=54.33, \mathrm{p}<0.0001$.

\section{A triple-correlated SOC component model}

We subsequently investigated the relationships between various coping resources and a triple-correlated SOC component model. We conducted a stepwise multiple regression, in which manageability entered first and explained $29.1 \%$ of the variance in cognitive resources, $\mathrm{F}(1,99)=42.07, \mathrm{p}<0.0001$. Meaningfulness entered second and explained a further $4.6 \%, F(1,98)=7.87, p=0.006$. Greater cognitive resources were associated with greater manageability and meaningfulness.

Manageability explained:

- $26.7 \%$ of the variance in social resources, $\mathrm{F}(1,99)=37.48, \mathrm{p}<0.0001$;

- $21.7 \%$ of the variance in emotional resources, $\mathrm{F}(1,99)=28.69, \mathrm{p}<0.0001$;

- $9.5 \%$ of the variance in spiritual/philosophical resources, $\mathrm{F}(1,99)=11.49, \mathrm{p}=0.001$;

- $13.9 \%$ of the variance in physical resources, $\mathrm{F}(1,99)=17.10, \mathrm{p}<0.0001$;

- $36.2 \%$ of the variance in global resources to cope with stress, $\mathrm{F}(1,99)=57.65, \mathrm{p}<0.0001$.

\section{A global SOC together with the triple-correlated SOC component model}

We calculated Pearson correlations before testing this model. Table 3 presents the correlations between the 4 independent variables, the global SOC and the three theoretically interrelated components.

Table 3 shows that there were high correlations between the global SOC and the three components, which was expected, because they propose to measure different facets of the same theoretical concept.

The global SOC entered first into the stepwise multiple regression, and explained $31 \%$ of the variance in cognitive resources, $\mathrm{F}(1,99)=46.52, \mathrm{p}<0.0001$.

Table 3. Pearson correlations between SOC variables

\begin{tabular}{lcccc}
\hline \multirow{2}{*}{ Variable } & \multicolumn{4}{c}{ Pearson correlations $^{\mathrm{a}}$} \\
\cline { 2 - 4 } & 1 & 2 & 3 & 4 \\
\hline 1. Comprehensibility & - & 0.65 & 0.42 & 0.86 \\
2. Manageability & & - & 0.65 & 0.89 \\
3. Meaningfulness & & - & 0.77 \\
4. Global SOC & & & - \\
\hline
\end{tabular}

SOC - sense of coherence.

${ }^{a}$ All correlations remain significant when the Bonferroni correction [31] is applied, with $\mathrm{p}<0.05(0.05 / 6=0.008)$. 
Manageability entered second and explained a further $3.5 \%, F(1,98)=7.91, p=0.006$. Greater cognitive resources were associated with greater global SOC and manageability.

The global SOC explained $25 \%$ of the variance in emotional resources, $\mathrm{F}(1,99)=34.59, \mathrm{p}<0.0001$.

Manageability explained:

- $27 \%$ of the variance in social resources, $\mathrm{F}(1,99)=37.48, \mathrm{p}<0.0001$;

- $9.5 \%$ of the variance in spiritual/philosophical resources, $\mathrm{F}(1,99)=11.49, \mathrm{p}=0.001$;

- $13.9 \%$ of the variance in physical resources, $\mathrm{F}(1,99)=17.10, \mathrm{p}<0.0001$;

- $36.2 \%$ of the variance in global resources to cope with stress, $\mathrm{F}(1,99)=57.65, \mathrm{p}<0.0001$.

\section{DISCUSSION}

We have shown that Swedish police officers have higher values of SOC and CRI than those of comparison groups. The results from our regression analyses show that manageability alone has a special significance for the various types of coping resources.

\section{SOC and coping resources for stress}

\section{in Swedish police officers}

All police officers who provide on-the-beat service in Sweden (all "sworn" officers) must undergo an education in fundamental police tactics that includes stress management and the development of communication skills. In order to qualify for this education, each police officer must be certified in basic Swedish national concepts of fundamental police tactics [22]. It is assumed that the education in fundamental basic tactics, together with a lifelong learning process, enhances the police officers' capacity to adapt to work-related stressors and potentially traumatic events. A network of peer support [32] is well organized in the Swedish police organization. This peer support comprises well-educated and experienced police officers or civilians who work at the departments. Every duty leader officer has been trained in detecting potential sources of traumatic stress, and it is necessary that she or he (or a special debriefing leader) should use the organization's resources effectively in order to quickly and correctly manage stress-induced situations when a potentially stressful event has occurred. The process of learning from experience is then expressed by each participant of a particular stressful event, which results in a perception of the stressful event that is shared by everybody. This enables the duty leader officer to promote the health of all police officers by focusing on resources, and not on the potentially negative consequences (which may lead to stress disorder). It is, therefore, not surprising that the police officers we studied had high values of both SOC and CRI (Tables 1 and 2). The officers, however, had low values for spiritual/philosophical resources for coping with stress. The values obtained on this scale are lower than those of American norms [17], but are similar to the values for a normal group presented in the Swedish manual for CRI ( $\mathrm{M}=28.2)$ [27]. The difference may, therefore, be due to cultural differences. This scale measures spiritual resources, and it may be that police officers are highly rational in their profession. It is difficult to discuss results from CRI, since data from other police populations are not available.

\section{Significance of the three SOC models}

\section{for various resources in stress situations}

The global SOC used in Model 1 explained approximately half of global CRI, and a great portion of the various coping resources. It explained emotional resources particularly well. The global SOC, however, plays a smaller role for spiritual/philosophical and physical resources, for which other variables play more important roles. Much of the variance in coping resources was 
not explained, and it is debatable whether any specific domain of SOC is more important than any other. For example, only $23 \%$ of the variance in social resources was explained by the global SOC, while $27 \%$ was explained by manageability alone in both Model 2 and Model 3. It is common to use the global SOC in salutogenic research; Eriksson and Lindström [24] stated that "no general pattern emerges regarding the importance of the three dimensions" (p. 462).

We examined the importance of the three components of SOC using Model 2, and showed that manageability is the most important of the three components. Manageability is the only component that significantly explained all the various resources for stress, except for cognitive resources. This was explained more fully by meaningfulness.

Global SOC entered the regression equation first in Model 3, in which the model is used to predict both cognitive and emotional resources. Only manageability explained any additional portion of the variance in cognitive resources. Manageability entered into the remaining regression equations first, indicating that this construct is particularly significant in the variation in resources used by police officers to cope with stress, and is worth being studied in future research. It is remarkable that manageability has this pattern of importance for social resources, in spite of the significant overlapping between cognitive, emotional and social resources.

\section{Limitations}

The structure of SOC in police officers has not been previously studied. In the work reported here we computed the global SOC as the sum of all items, as is customary. It should be stressed that the model consists of a single factor construct that includes all the items of the SOC-29 scale, and that this may fit the data rather poorly. We used Antonovsky's [2] theoretical item grouping when calculating results for each SOC component, which may be a limitation, because the factorial structure of the three components of SOC-29 has not been completely examined by modern Structural Equation Modeling techniques in different populations. An agreement has not been reached. Schumann et al. [33], for example, used traditional principal component analysis and showed that one factor fitted data from a representative general German population, while Bengtsson-Tops et al. [34] examined Swedish outpatients with schizophrenia and showed that a four-factor solution is necessary. A factor analysis of the present data was, however, outside the scope of the present study. Further research will determine whether one, three or four components should be used to fit the data in the population of police officers.

There were gender differences in the population we studied (women were younger, and had lower scores in global SOC and comprehensibility). We did not, however, use gender as a covariate in the regression analyses, because men and women did not differ in the length of experience as police officers. We argued that experience from work is more important than age in the development of both SOC and the various coping resources for stress in the daily work of police officers. Durm and Glaze [35] showed that women with high self-reported stress had high scores for cognitive and emotional resources, which was the opposite in men. Stress was, however, not measured in our study, and we did not find gender differences in any kind of coping resources.

\section{Implications}

The study presented here focused on salutogenesis [36], the origin of well-being, and not on negative outcomes.

We hope that researchers will use models similar to the models presented here before they draw conclusions that develop Antonovsky's [2] theory further, and before they implement it into a learning model [37]. We further hope that this study will stimulate further research on the theory and factor structure of SOC. 


\section{Conclusions and some suggestions}

It may be more favorable to interpret an outcome variable when SOC components are analyzed as dependent variables at the component level rather than at the level of a global measure, in a case in which the SOC components are only moderately correlated with one another. Manageability is the most important component of SOC for various coping resources in stress situations for police officers, and we suggest that this component should be studied separately.

Learning develops organizations and employees, and the theory of Antonovsky [2], which is based on resources, may be integrated into a learning model [37]. Work and its conditions are generally important for most people. At a good workplace, especially in an organization with a high risk of stress-related work, the employees endeavor to develop coping resources that can be used in situations of stress. A good workplace offers adequate training and further education. We have studied a sample from the population of Swedish police officers who must undergo education in fundamental police tactics that includes stress management and the development of communication skills. In the present study we have shown that Swedish police officers had a relatively high sense of coherence and that they had relative good coping resources, indicating an important source of resilience and protection of their health while working with daily stress. Salutogenesis, the origin of wellbeing, should be more in focus of future research on workplaces with a high level of occupational stress, instead on different origins of stress per se.

\section{ACKNOWLEDGEMENTS}

We presented preliminary results from this study at the conference "SALUS 2012: The good workplace - sustainable working", Trollhättan, Sweden, and held discussions there with researchers and practitioners interested in health factors in the workplace. We are grateful to the participants for volunteering their time and effort to complete the tests required for the investigation; Avishai Antonovsky, Ph.D., and Monika Eriksson, Ph.D., for permission to the use the SOC-29; police chief and operative leader Per Ågren for permission to interview police officers during on-duty hours; Forum for Work-Integrated Learning and Pedagogic Development at University West for financial support to the first author for preparation of this article; and Dr. George Farrants for reviewing our English.

\section{REFERENCES}

1. Schwarzer R, Bowler RM, Cone JE. Social integration buffers stress in New York police after the 9/11 terror attack. Anxiety Stress Coping. 2014;27(1):18-26, http://dx.doi.org/10.1080/10 615806.2013.806652.

2. Antonovsky A. Unraveling the mystery of health: how people manage stress and stay well. San Francisco: Jossey-Bass; 1987.

3. Eriksson M, Lundström B. Antonovsky's sense of coherence scale and the relation with health: A systematic review. J Epidemiol Com Health. 2006;60:376-81, http://dx.doi. org/10.1136/jech.2005.041616.

4. Hochwälder J. Negative life events and mental ill-health among women: A prospective study of the main, moderating and mediating effect of sense of coherence. J Happiness Stud. 2013;14(6):1739-50, http://dx.doi.org/10.1007/s10902012-9407-6.

5. Nielsen MB, Matthiesen SB, Einarsen S. Sense of coherence as a protective mechanism among targets of workplace bullying. J Occup Health Psychol. 2008;13:128-36, http://dx.doi. org/10.1037/1076-8998.13.2.128.

6. Ogińska-Bulik N. The role of personal and social resources in preventing adverse health outcomes in employees of uniformed professions. Int J Occup Med Environ Health. 2005;18:233-40.

7. Basińska MA, Andruszkiewicz A, Grabowska M. Nurses' sense of coherence and their work related patterns of behavior. Int J Occup Med Environ Health. 2011;24:256-366, http://dx.doi.org/10.2478/S13382-011-0031-1. 
8. Anshel MH. A conceptual model and implications for coping with stressful events in police work. Crim Justice Behav. 2000;27:375-400, http://dx.doi.org/10.1177/0093854800 027003006

9. Violanti JM, Aron F. Sources of police stressors, job attitudes, and psychological distress. Psychol Rep. 1994;72:899904, http://dx.doi.org/10.2466/pr0.1993.72.3.899.

10. Brown JM, Campbell EA. Sources of occupational stress in the police. Work Stress. 1990;4:305-18, http://dx.doi. org/10.1080/15228930802282014.

11. Kassen M, DiLalla D. Maladaptive defense style and traumatic stress reactions in a specialized unit of the South African police service. J Forensic Psychol Pract 2012;8:262-79, http://dx.doi.org/10.1111/sjop.12020.

12. Dåderman AM, Fredriksson B, Kristiansson M, Nilsson L-H, Lidberg L. Violent behavior, impulsive decision-making, and anterograde amnesia while intoxicated with flunitrazepam and alcohol or other drugs: A case study in forensic psychiatric patients. J Am Acad Psych Law. 2002;30:238-51.

13. Kähönen K, Näätänen P, Tolvanen A. Salmela-Aro K. Development of sense of coherence during two group interventions. Scand J Psychol. 2012;53:523-7, http://dx.doi. org/10.1111/sjop.12020.

14. Dudek B, Szymczak W. The role of cognitive schemata in the development of posttraumatic stress disorder: Results of cross-sectional and longitudinal studies. Int J Occup Med Environ Health. 2011;24(1):29-35, http://dx.doi.org/10.2478/ s13382-011-0010-6.

15. Feldt T, Rasku A. The structure of Antonovsky's Orientation to Life Questionnaire. Pers Indiv Diff. 1998;25:505-16, http://dx.doi.org/10.1016/S0191-8869(98)00077-4.

16. Lazarus RS, Folkman S. The concept of coping. In: Monat A, Lazarus RS, editors. Stress and coping: An anthology. 3rd ed. New York: Columbia University; 1991. p. 189-206.

17. Marting MS, Hammer LA. Coping Resource Inventory manual and sampler set revised. Menlo Park, CA: Mind Garden; 1988, 2004.
18. Pearlin LI, Schooler C. The structure of coping. J Health Soc Behav. 1978;19:2-21.

19. Emilsson S, Svensk A-C, Tavelin B, Lindh J. Support group participation during the post-operative radiotherapy period increases levels of coping resources among women with breast cancer. Eur J Cancer Care. 2012:21(5):591-8, http:// dx.doi.org/10.1111/j.1365-2354.2012.01343.x.

20. Steyn C, Howcroft JG, Fouché JP. The psychofortology of female psychiatric out-patients living with mood and anxiety disorders. S Afr J Psychol. 2011;41:288-99, http://dx.doi. org/10.1177/008124631104100304.

21. Zeidner M, Hammer A. Life events and coping resources as predictors of stress symptoms in adolescents. Personal Indiv Diff. 1990;11:693-703, http://dx.doi.org/10.1016/01918869(90)90254-O.

22. Swedish National Police Board. National basic police tactics: Training material. Solna: Swedish National Police Academy; 2005.

23. Gruszczyńska E. What is measured by the Orientation to Life Questionnaire? Construct validity of the instrument for the Sense of Coherence measurement. Pol Psychol Bull. 2006;37:74-83.

24. Eriksson M, Lundström B. Validity of Antonovsky's Sense of Coherence Scale - A systematic review. J Epidemiol Com Health. 2005;59:460-6, http://dx.doi.org/10.1136/ jech.2003.018085.

25. Cronbach LJ. Coefficient $\alpha$ and the internal structure of tests. Psychometrica. 1951;16:297-334, http://dx.doi.org/10.1007/ BF02310555.

26. Nunnally J. Psychometric theory. New York: McGrawHill; 1978.

27. Ekecrantz L, Norman M. [Instructions for the Coping Resources Inventory - CRI]. Stockholm: Psykologiförlaget; 1991. Swedish.

28. Eysenck HJ, Eysenck SBG. Manual for the Eysenck Personality Questionnaire. San Diego, CA: Educational and Industrial Testing Service; 1975. 
29. Block J. Tests \& Reviews: Personality. Eysenck Personality Questionnaire. In: Buros OK, editor. Eighth Mental Measurement Yearbook. Vol. 1. Highland Park, New Jersey: Gryphom Press; 1978. p. 805-9.

30. Antonovsky A. The structure and properties of the sense of coherence scale. Soc Sci Med. 1993;36:725-33, http://dx.doi. org/10.1016/0277-9536(93)90033-Z.

31. Howell DC. Statistical methods for psychology. 4th ed. Belmont, CA: Duxbury; 1997.

32. Creamer MC, Varker T, Bisson J, Darte K, Greenberg N, Lau W, et al. Guidelines for peer support in high risk organizations: An international consensus study using the Delphi method. J Trauma Stress. 2012;25:134-41, http://dx.doi. org/10.1002/jts.21685.

33. Schumann A, Hapke U, Meyer C, Rumpf H-J, John U. Measuring Sense of Coherence with only three items: A useful tool for population surveys. Br J Health Psychol. 2003;8: 409-21, http://dx.doi.org/10.1348/135910703770238275.
34. Bengtsson-Tops A, Brunt D, Rask M. The structure of Antonovsky's sense of coherence in patients with schizophrenia and its relationship to psychopathology. Scand J Caring Sci. 2005;19:280-7, http://dx.doi.org/10.1111/j.1471-6712. 2005.00342.x.

35. Durm MW, Glaze P. Sex, perception of immediate stress, and response to coping resources inventory, emotional domain. Psychol Rep. 2002;90:270-2, http://dx.doi.org/10.2466/ pr0.2002.90.1.270.

36. Lindström B, Eriksson M. Salutogenesis. J Epidemiol Com Health. 2005;59:440-2, http://dx.doi.org/10.1136/jech. 2005.034777 .

37. Lindström B, Eriksson M. From health education to healthy learning: Implementing salutogenesis in educational science. Scand J Public Health. 2011;39(Suppl 6):85-92, http:// dx.doi.org/10.1177/1403494810393560.

This work is available in Open Access model and licensed under a Creative Commons Attribution-NonCommercial 3.0 Poland License - http://creativecommons.org/ licenses/by-nc/3.0/pl/deed.en. 